\title{
Thermophysical characteristics of radioactive graphite - water vapor system
}

\author{
Nikolaj Barbin ${ }^{1,2,3,{ }^{*}, \text { Anton Kobelev }}{ }^{1}$, Dmitrij Terent'ev ${ }^{1}$, and Sergej Alekseev ${ }^{1,4}$ \\ ${ }^{1}$ Ural State Fire Service Institute of Emercom of Russia, 620062 Ekaterinburg, Russia \\ ${ }^{2}$ Ural State Agrarian University, 620075 Ekaterinburg, Russia \\ ${ }^{3}$ Ural Federal University named after the first President of Russia B.N. Yeltsin, 620002 Ekaterinburg, \\ Russia \\ ${ }^{4}$ SEC Reliability and Safety of Large Systems of Ural Branch of RAS, 620049 Ekaterinburg, Russia
}

\begin{abstract}
The article considers thermophysical characteristics of radioactive graphite - water vapor system in temperature range 373$3273 \mathrm{~K}$. The research was made by thermodynamic modeling method using TERRA software. We determined 4 temperature intervals in which changes of thermophysical characteristics of radioactive graphite - water vapor system occur.
\end{abstract}

Most of atomic power plants operate according to the scheme where low-enriched uranium is served as a fuel for thermal reactors, graphite is used as a moderator material, and water is used as a reactor coolant. [1].

In Russia and other countries in the world there is a problem of handling with radioactive graphite of uranium-graphite reactive cores after their taking out of service [2].

Radionuclides $\left({ }^{137} \mathrm{Cs},{ }^{90} \mathrm{Sr},{ }^{154} \mathrm{Eu}\right.$ and others) are formed in graphite due to the leak of reactor coolant and transfer of fuel segments.

There are several methods of treatment of radioactive graphite: "Conservation", "Disposal", "Elimination" [3]. First two methods require the construction of deep storages and large financial costs. Method "Elimination" is more effective as the amount of irradiated graphite falls by 90 times [4].

Elimination of irradiated graphite can be performed by the following methods: oxidation by salts, oxidation in molten alkali and carbonates, liquid-phase oxidation in acids, bonding of graphite with metals, oxidation by air, oxygen, carbon dioxide, water vapor [3-6].

The purpose of this research is to study thermophysical characteristics of radioactive graphite - water vapor system in temperature range 373-3273 K.

The tasks of the study are carrying out the experiment with investigated system by thermodynamic modeling method, analysis of thermophysical characteristics $(\mathrm{V}$ - specific volume $\left(\mathrm{m}^{3} / \mathrm{kg}\right), \mathrm{S}$ - entropy $(\mathrm{kJ} /(\mathrm{kg} \mathrm{K})), \mathrm{I}$ - total enthalpy $(\mathrm{kJ} / \mathrm{kg}), \mathrm{U}$ - total internal energy $(\mathrm{kJ} / \mathrm{kg}), \mathrm{M}$ - number of moles (mole/kg), $\mathrm{Z}$ - mass fraction of condensed phases).

Full-scale experiments do not always give reliable information at high temperatures due to their complexity and measurements errors. So, calculations were made by

* Corresponding author: NMBarbin@mail.ru 
thermodynamic modeling using TERRA software which is used for studying systems with complex chemical composition in high temperature conditions.

The software is used to calculate phase composition, thermodynamic and transport properties of arbitrary systems.

The calculation of phase composition and characteristics of equilibrium was made according to reference database for properties of individual substances. The basis of information in the database are thermodynamic, thermophysical and thermochemical properties of individual substances systemized in the Institute of High Temperatures of the Russian Academy of Sciences (database INVATERMO), by national US Bureau of Standards, calculated in Moscow State Technical University using molecular calorimetric and spectrochemical data, published in reference books [7, 8].

Thermodynamic modeling with the use of TERRA software is successfully used in thermal physics $[5,6]$.

Thermodynamical modeling was carried out at initial pressure of one atmosphere, at initial temperature $373 \mathrm{~K}$ and at final temperature $3273 \mathrm{~K}$. Temperature measurement interval $-100 \mathrm{~K}$. Phase composition: gaseous phase $-75 \%\left(\mathrm{H}_{2} \mathrm{O}-100 \%\right.$ mass $)$, condensed phase $-25 \%$ (C $\sim 99.98 \%$ mass, $\mathrm{U} \sim 1.1510^{-2} \%$ mass, $\mathrm{Cl} \sim 1.8810^{-3} \%$ mass, $\mathrm{Ca} \sim 2.6910^{-4} \%$ mass, $\mathrm{Pu} \sim 7.1910^{-5} \%$ mass, Be $\sim 1.1910^{-5} \%$ mass, $\mathrm{Ni} \sim 7.9910^{-6} \%$ mass, $\mathrm{Cs} \sim 3.9910^{-6} \%$ mass, $\mathrm{Sr} \sim 9.9910^{-6} \%$ mass, Am $\sim 9.9910^{-6} \%$ mass, $\mathrm{Eu} \sim 7.9910^{-6} \%$ mass.

Figure 1a shows dependence of specific volume on temperature. In temperature range from 373 to $573 \mathrm{~K}$ specific volume of the system increases from 1.29 to $2.01 \mathrm{~m}^{3} / \mathrm{kg}$. At temperature $573 \mathrm{~K}$ the bend point is observed and in temperature range from 573 to $973 \mathrm{~K}$ specific volume increases from 2.01 to $4.98 \mathrm{~m}^{3} / \mathrm{kg}$. At temperature $973 \mathrm{~K}$ the bend point is observed and in temperature range 973-2373 K specific volume increases from 4.98 to $12.38 \mathrm{~m}^{3} / \mathrm{kg}$. At temperature $2373 \mathrm{~K}$ the bend is observed and in temperature range from 2373 to $3273 \mathrm{~K}$ specific volume increases from 12.38 to $19.7 \mathrm{~m}^{3} / \mathrm{kg}$.

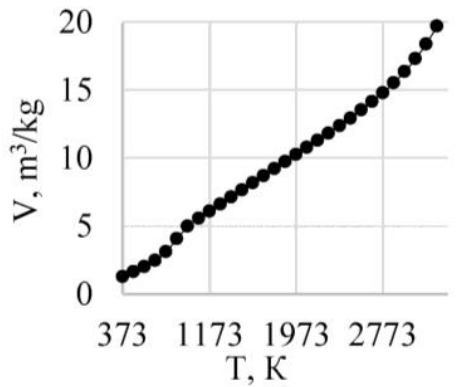

a)

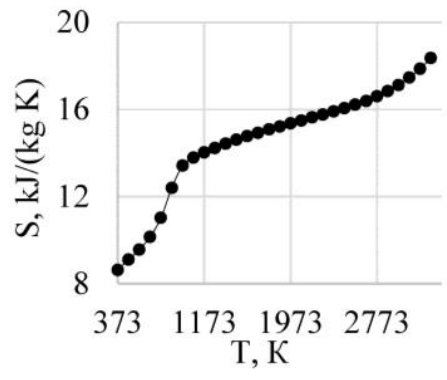

b)

Fig. 1. Dependences of thermophysical characteristics of radioactive graphite - water vapor system on temperature: a) dependence of specific volume on temperature, b) dependence of entropy on temperature.

Figure $1 \mathrm{~b}$ shows dependence of entropy on temperature. In temperature range from 373 to $573 \mathrm{~K}$ entropy increases from 8.63 to $9.56 \mathrm{~kJ} /(\mathrm{kg} \mathrm{K})$. At temperature $573 \mathrm{~K}$ the bend point is observed and in temperature range from 573 to $973 \mathrm{~K}$ entropy increases from 9.56 to $13.41 \mathrm{~kJ} /(\mathrm{kg} \mathrm{K})$. At temperature $973 \mathrm{~K}$ the bend point is observed and in temperature range $973-2373 \mathrm{~K}$ entropy increases from 13.41 to $15.89 \mathrm{~kJ} /(\mathrm{kg} \mathrm{K})$. At temperature $2373 \mathrm{~K}$ the bend is observed and in temperature range from 2373 to $3273 \mathrm{~K}$ entropy increases from 15.89 to $18.35 \mathrm{~kJ} /(\mathrm{kg} \mathrm{K})$.

Figure 2a shows dependence of total enthalpy on temperature. In temperature range from 373 to $573 \mathrm{~K}$ total enthalpy increases from -9873.53 to $-9432.54 \mathrm{~kJ} / \mathrm{kg}$. At temperature $573 \mathrm{~K}$ the bend point is observed and in temperature range from 573 to $973 \mathrm{~K}$ 
total enthalpy increases from -9432.54 to $-6368.44 \mathrm{~kJ} / \mathrm{kg}$. At temperature $973 \mathrm{~K}$ the bend point is observed and in temperature range 973-2373 K total enthalpy increases from 6368.44 to $-2482.69 \mathrm{~kJ} / \mathrm{kg}$. At temperature $2373 \mathrm{~K}$ the bend is observed and total enthalpy increases from -2482.69 to $4704.91 \mathrm{~kJ} / \mathrm{kg}$.

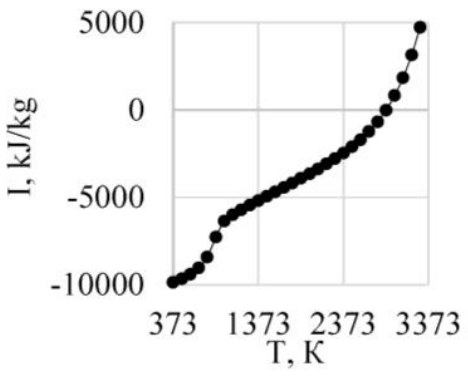

a)

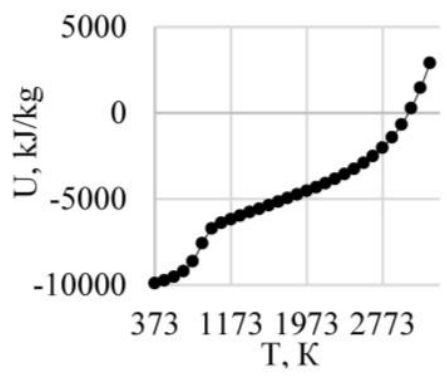

b)

Fig. 2. Dependences of thermophysical characteristics of radioactive graphite - water vapor system on temperature: a) dependence of total enthalpy on temperature, b) dependence of total internal energy on temperature.

Figure $2 \mathrm{~b}$ shows dependence of total internal energy on temperature. In temperature range from 373 to $573 \mathrm{~K}$ total internal energy increases from -9899.44 to $-9529.15 \mathrm{~kJ} / \mathrm{kg}$. At temperature $573 \mathrm{~K}$ the bend point is observed and in temperature range from 573 to 973 $\mathrm{K}$ total internal energy increases from -9529.15 to $-6713.87 \mathrm{~kJ} / \mathrm{kg}$. At temperature $973 \mathrm{~K}$ the bend point is observed and in temperature range $973-2373 \mathrm{~K}$ total internal energy increases from -6713.87 to $-3565.17 \mathrm{~kJ} / \mathrm{kg}$. At temperature $2373 \mathrm{~K}$ the bend is observed and total internal energy increases from -3565.17 to $2914.22 \mathrm{~kJ} / \mathrm{kg}$.

Figure $3 \mathrm{a}$ shows dependence of number of component moles on temperature. In temperature range from 373 to $573 \mathrm{~K}$ number of component moles in the system decreases from 52.5 to $46.4 \mathrm{~mole} / \mathrm{kg}$. At temperature $573 \mathrm{~K}$ the bend point is observed and in temperature range from 573 to $973 \mathrm{~K}$ number of component moles increases from 46.4 to $61.5 \mathrm{~mole} / \mathrm{kg}$. At temperature $973 \mathrm{~K}$ the bend point is observed and in temperature range 973-2373 K number of component moles doesn't change and is equal to $62 \mathrm{~mole} / \mathrm{kg}$. At temperature $2373 \mathrm{~K}$ the bend is observed and number of component moles increases from 62.7 to $72.3 \mathrm{~mole} / \mathrm{kg}$.

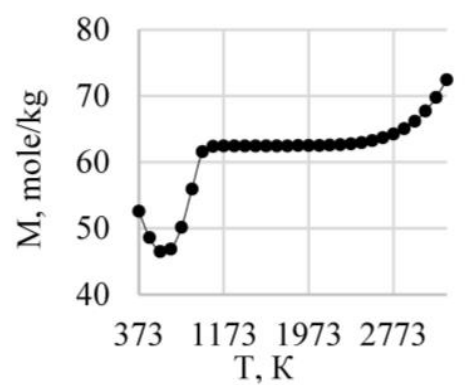

a)

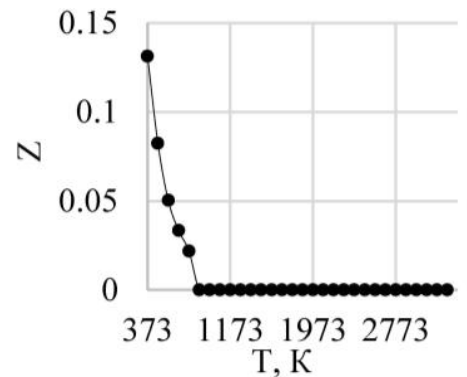

b)

Fig. 3. Dependences of thermophysical characteristics of radioactive graphite - water vapor system on temperature: a) dependence of number of component moles on temperature, b) dependence of mass fraction of condensed phases on temperature.

Figure $3 \mathrm{~b}$ shows dependence of mass fraction of condensed phases on temperature. In temperature range from 373 to $573 \mathrm{~K}$ mass fraction of condensed phases decreases from 
0.13 to 0.05 . At temperature $573 \mathrm{~K}$ the bend point is observed and in temperature range from 573 to $873 \mathrm{~K}$ mass fraction of condensed phases decreases from 0.05 to 0 .

Condensed $\mathrm{C}$ gives the main contribution to thermodynamic properties of the system till its burning temperature $(873 \mathrm{~K})$. At temperature $>873 \mathrm{~K}$ thermodynamic properties are defined by gaseous phase.

According to the Figure four temperature intervals where changes of thermophysical properties of the system occur are marked.

1 temperature range from 373 to $573 \mathrm{~K}$ : changes are connected with the increasing of $\mathrm{CH}_{4}$ gas content.

2 temperature range from 573 to $973 \mathrm{~K}$ : changes are connected with both decreasing of $\mathrm{CH}_{4}$ gas content and burning of condensed $\mathrm{C}$.

3 temperature range from 973 to $2373 \mathrm{~K}$ : changes have a linear behavior and are defined by gas-vapor phase.

4 temperature range $>2373 \mathrm{~K}$ : changes are connected with thermal decomposition of gas-vapor phase.

\section{References}

1. W.S. Yang, Advances in reactor concepts: Generation IV reactors (Purdue University, West Lafayette, 2014)

1. Nuclear Power Reactors in the World (International atomic energy agency, Vienna, 2015)

2. Predisposal Management of Radioactive Waste from Nuclear Power Plants and Research Reactors (International atomic energy agency, Vienna, 2016)

3. A.M. Grin'ko, V.V. Tokarevskij, Materials 5th international conference "Cooperation for solving the problem of waste» (Kharkiv National University of Economics, Kharkiv, 2008)

4. N.M. Barbin, D.I. Terentiev, S.G. Alexeev, T.M. Barbina, J. Radioanal. Nucl. Chem. 307, 1459 (2016)

5. N.M. Barbin, D.I. Terentiev, S.G. Alexeev, T.M. Barbina, J. Radioanal. Nucl. Chem. 299, 1747 (2014)

6. V.E. Alemasov, A.F. Dregalin, A.P. Tishin, Thermodynamic and thermophysical properties of combustion products (VINITI, Moscow, 1971)

7. L.V. Gurvich, I.V. Vejc, V.L. Medvedev, Thermodynamic properties of individual substances (Science, Moscow, 1982) 